This item was submitted to Loughborough's Research Repository by the author.

Items in Figshare are protected by copyright, with all rights reserved, unless otherwise indicated.

\title{
Dehydration of amides to nitriles under conditions of a catalytic appel reaction
}

\section{PLEASE CITE THE PUBLISHED VERSION}

https://doi.org/10.1021/acs.orglett.7b03862

\section{PUBLISHER}

(c) American Chemical Society (ACS)

\section{VERSION}

AM (Accepted Manuscript)

\section{PUBLISHER STATEMENT}

This work is made available according to the conditions of the Creative Commons Attribution-NonCommercialNoDerivatives 4.0 International (CC BY-NC-ND 4.0) licence. Full details of this licence are available at: https://creativecommons.org/licenses/by-nc-nd/4.0/

\section{LICENCE}

CC BY-NC-ND 4.0

\section{REPOSITORY RECORD}

Shipilovskikh, Sergei A., Vladimir Yu Vaganov, Elena I. Denisova, Aleksandr E. Rubtsov, and Andrei Malkov. 2019. "Dehydration of Amides to Nitriles Under Conditions of a Catalytic Appel Reaction". figshare. https://hdl.handle.net/2134/28285. 


\title{
Dehydration of Amides to Nitriles under Conditions of a Catalytic Appel Reaction
}

\author{
Sergei A. Shipilovskikh, ${ }^{\dagger}$ Vladimir Yu. Vaganov, ${ }^{\dagger}$ Elena I. Denisova, ${ }^{\dagger}$ Aleksandr E. Rubtsov, ${ }^{* \dagger}$ Andrei \\ V. Malkov ${ }^{*} \S$ \\ † Department of Chemistry Perm State University, Bukireva 15, Perm 614990, Russia \\ ¥ Department of Chemistry, Loughborough University, Loughborough, Leics LE11 3TU, UK \\ $\S$ Department of Organic Chemistry, RUDN University, 6 Miklukho-Maklaya Street, Moscow 117198, Russia \\ Supporting Information Placeholder
}

$\stackrel{\mathrm{O}}{\mathrm{N}}_{\mathrm{NH}_{2}}$

$\mathrm{R}=\mathrm{Alk}, \mathrm{Ar}$

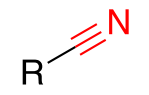

18 examples

$80-98 \%$ yield

ABSTRACT: A highly expedient protocol for a catalytic Appel-type dehydration of amides to nitriles has been developed, which employs oxalyl chloride, triethylamine and triphenylphosphine oxide as a catalyst. The reactions are usually complete in less than 10 min with only $1 \mathrm{~mol} \%$ of catalysts loading. The reaction scope includes aromatic, heteroaromatic and aliphatic amides, including derivatives of $\alpha$-hydroxy and $\alpha$-amino acids.

Chemical compounds with the nitrile functional group serve as useful precursors in the manufacture of a large variety of consumer products, such as polyamides, pigments and dyes, pharmaceuticals, agrochemicals and many other substances. ${ }^{1}$ The nitrile group has a rich chemistry, since it can be conveniently converted to other functional groups. ${ }^{2}$ Also, the nitrile pharmacophore plays a significant role in modulating the biological activity of synthetic medicinal drugs ${ }^{3}$ and natural products. ${ }^{4}$

The synthesis of nitriles by the dehydration of primary amides is a well-known process; numerous methods have been developed and used by practicing chemists for over a century. ${ }^{5}$

In the last few years, a number of new methods have emerged for carrying out an efficient dehydration of amides to nitriles. Among the new reagents, $\left[\mathrm{Et}_{2} \mathrm{NSF}_{2}\right] \mathrm{BF}_{4}$ (XtalFluor-E) ${ }^{6}$ and silicotungstate $\left[n-\mathrm{Bu}_{4} \mathrm{~N}\right]_{4}\left[\alpha-\mathrm{H}_{4} \mathrm{SiW}_{11} \mathrm{O}_{39}\right]^{7}$ were introduced. Also, metal catalyzed dehydration has been carried out in the presence of silanes, ${ }^{8} N$-methyl- $N$-(trimethylsilyl)trifluoroacetamide ${ }^{9}$ and acetonitrile. $^{10}$

However, in many instances the practicality of the methods is offset by the toxicity of the reagents, slow reaction times, narrow scope and the laborious workup needed to remove the side products. Therefore, the development of convenient, practical methods for converting amides to nitriles still holds its relevance.

The Appel ${ }^{11}$ reaction, which employs a combination of $\mathrm{Ph}_{3} \mathrm{P}$, $\mathrm{CCl}_{4}$ and $\mathrm{Et}_{3} \mathrm{~N}$, belongs to a group of highly versatile tools that, among other useful transformation, ${ }^{12}$ can be used for the synthesis of nitriles from amides (Scheme 1, A).

\section{A. The original Appel protocol}

\begin{tabular}{|c|c|c|}
\hline $\mathrm{NH}_{3}$ & $\begin{array}{l}\mathrm{CCl}_{4} \text { (1 equiv) } \\
\mathrm{Et}_{3} \mathrm{~N}(1 \text { equiv }) \\
\mathrm{Ph}_{3} \mathrm{P}(1.25 \text { equiv) }\end{array}$ & $\geqslant N$ \\
\hline $\mathrm{R}=\mathrm{H}, \mathrm{Alk}, \mathrm{Ar}$ & $\begin{array}{c}\mathrm{CHCl}_{3}, 60^{\circ} \mathrm{C}, 6 \mathrm{~h} \\
\text { ref } 11\end{array}$ & $50-92 \%$ yield \\
\hline
\end{tabular}

\section{B. This work}

\begin{tabular}{|c|c|}
\hline $\mathrm{NH}_{2}^{\mathrm{O}}$ & $\begin{array}{l}(\mathrm{COCl})_{2}(2 \text { equiv }) \\
\mathrm{Et}_{3} \mathrm{~N}(3 \text { equiv }) \\
\mathrm{Ph}_{3} \mathrm{PO}(1 \mathrm{~mol} \%)\end{array}$ \\
\hline Alk, Ar & $\mathrm{MeCN}, \mathrm{rt}, 10 \mathrm{~min}$ \\
\hline
\end{tabular}<smiles>[R]C#N</smiles>

$80-98 \%$ yield

Scheme 1. Dehydration of amides to nitriles by Appel reaction.

However, the original Appel protocol has a number of weaknesses. First of all, exposure to $\mathrm{CCl}_{4}$ can lead to kidney damage, it is also a suspected carcinogen. Furthermore, it contributes to depletion of the ozone layer and can no longer be used. ${ }^{13}$ Secondly, stoichiometric use of $\mathrm{Ph}_{3} \mathrm{P}$ results in the formation of large quantities of $\mathrm{Ph}_{3} \mathrm{PO}$, which complicates the isolation and purification of the target products. Therefore, the development of a catalytic version of the Appel dehydration of amides, where $\mathrm{CCl}_{4}$ as a source of chloride is replaced by a safer alternative, and the phosphorus reagent is used as an organic catalyst, while keeping the universal application scope of the original method, would make it significantly more attractive from the practical 
standpoint. Our work was inspired by the recent reports of Denton $^{14}$ and others, ${ }^{15}$ who have demonstrated that running some reactions under the Appel conditions can be efficient using catalytic $\mathrm{Ph}_{3} \mathrm{PO}$ in the presence of oxalyl chloride.

In this work, we present an adaptation of this protocol to a mild and facile conversion of amides to nitriles using as low as 1 mol \% loading of $\mathrm{Ph}_{3} \mathrm{PO}$ (Scheme 1, B).

Table 1. Optimization of reaction conditions. ${ }^{a}$

\begin{tabular}{|c|c|c|c|c|c|}
\hline $\mathbf{1 a}$ & $\mathrm{NH}_{2}$ & $\begin{array}{l}(\mathrm{COCl})_{2} \\
\mathrm{Ph}_{3} \mathrm{PO} \\
\mathrm{MeCN}, \mathrm{rt}\end{array}$ & $=t_{3} N$ & $\mathrm{Ph}^{-}$ & \\
\hline entry & $\begin{array}{l}(\mathrm{COCl})_{2} \\
\text { (equiv) }\end{array}$ & $\begin{array}{l}\mathrm{Ph}_{3} \mathrm{PO} \\
\text { (mol \%) }\end{array}$ & $\begin{array}{l}\mathrm{Et}_{3} \mathrm{~N} \\
\text { (equiv) }\end{array}$ & solvent & $\begin{array}{l}\text { conv } \\
(\%)^{b}\end{array}$ \\
\hline 1 & 1 & - & - & $\mathrm{MeCN}$ & $0^{c}$ \\
\hline 2 & 1 & - & 1 & $\mathrm{MeCN}$ & $0^{d}$ \\
\hline 3 & 1 & 100 & - & $\mathrm{MeCN}$ & 25 \\
\hline 4 & 1 & 10 & 1 & $\mathrm{MeCN}$ & 14 \\
\hline 5 & 1 & 10 & 2 & MeCN & 29 \\
\hline 6 & 1 & 10 & 3 & $\mathrm{MeCN}$ & 45 \\
\hline 7 & 2 & 10 & 3 & $\mathrm{MeCN}$ & 100 \\
\hline 8 & 2 & 10 & 2 & $\mathrm{MeCN}$ & 75 \\
\hline 9 & 2 & 5 & 3 & $\mathrm{MeCN}$ & 100 \\
\hline 10 & 2 & 2 & 3 & $\mathrm{MeCN}$ & 100 \\
\hline 11 & 2 & 1 & 3 & $\mathrm{MeCN}$ & 100 \\
\hline 12 & 2 & 1 & 3 & $\mathrm{Et}_{2} \mathrm{O}$ & 87 \\
\hline 13 & 2 & 1 & 3 & $\mathrm{CH}_{2} \mathrm{Cl}_{2}$ & 85 \\
\hline 14 & 2 & 1 & 3 & toluene & 77 \\
\hline 15 & 2 & 1 & 3 & dioxane & 31 \\
\hline
\end{tabular}

${ }^{\mathrm{a}}$ General conditions: benzamide 1a $(0.25 \mathrm{mmol}), \mathrm{Ph}_{3} \mathrm{PO}, \mathrm{Et}_{3} \mathrm{~N}$, dry $\mathrm{MeCN}(1 \mathrm{ml})$, dropwise addition of neat $(\mathrm{COCl})$ 2. The reactions were carried out for $10 \mathrm{~min}$ at rt before an aliquot $(50 \mu \mathrm{L})$ was taken, quenched with aqueous MeCN (1 mL) and analyzed by GC. ${ }^{b}$ Conversion to nitrile 2a was calculated from GC. 'After $10 \mathrm{~min}$, according to GC, the reaction mixture contained 1a (70\%) and benzoyl isocyanate 3a (ca. 25\%). ${ }^{\mathrm{d}}$ After $10 \mathrm{~min}$, according to GC, the reaction mixture contained 1a (60\%), benzoyl isocyanate 3a (ca. $21 \%$ ) and some unidentified by-products.

The investigation commenced with establishing the best conditions for the dehydration of amides which employ benzamide 1a as a model substrate (Table 1). First, the role of each reagent was evaluated. Thus, oxalyl chloride on its own did not produce benzonitrile 2a (entry 1). Instead, a slow formation of benzoyl isocyanate 3a was observed, mirroring published data. ${ }^{\mathbf{1 6}}$ This reaction is likely to proceed through the initial $O$-acylation of 1a to give oxalyl imidate 4 followed by cyclization into unstable 2-phenyloxazolin-4,5-dione 5, which then forms benzoyl isocyanate 3a (Scheme 2). Addition of triethylamine to the reaction mixture did not alter the reaction outcome (entry 2), which contrasts with the previously reported formation of benzonitrile 2a when benzamide 1a was treated with oxalyl chloride in the presence of 2.6-lutidine. ${ }^{\mathbf{1 6 a}}$

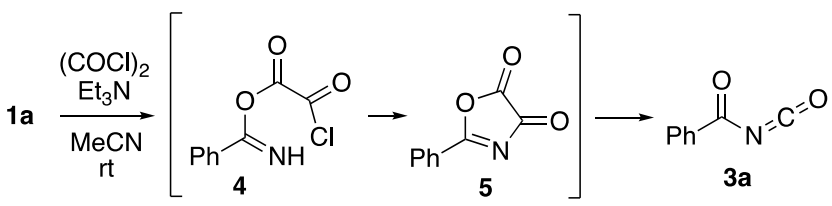

Scheme 2. Formation of benzoyl isocyanate 3a.

The use of stoichiometric quantities of $\mathrm{Ph}_{3} \mathrm{PO}$ and $(\mathrm{COCl})_{2}$ without triethylamine resulted in a low conversion of $\mathbf{1 a}$ into $\mathbf{2 a}$ (entry 3). With $10 \mathrm{~mol} \%$ of $\mathrm{Ph}_{3} \mathrm{PO}$ and 1 equiv each of oxalyl chloride and trimethylamine, benzonitrile $\mathbf{2 a}$ was formed in a $14 \%$ conversion (entry 4 ), which increased to $29 \%$ and $45 \%$ when triethylamine was used in two- and threefold excess, respectively (entries 5 and 6). Full conversion was achieved when the amount of $(\mathrm{COCl})_{2}$ was doubled to 2 equiv (entry 7). Note that the reaction was complete in less than $10 \mathrm{~min}$. A threefold excess of triethylamine appears to be crucial, as reducing it to 2 equiv slowed the reaction down (entry 8).

Next, the effect of the catalyst loading was investigated (entries 9-11). Pleasingly, $\mathrm{Ph}_{3} \mathrm{PO}$ performed efficiently even when the loading was as low as $1 \mathrm{~mol} \%$ (entry 11). With benzamide 1a, the catalyst content could be further reduced, but for investigating the reaction scope, $1 \mathrm{~mol} \%$ proved to be most suitable. The influence of the solvent was briefly assessed (entries 1215). Despite some good conversions achieved in $\mathrm{Et}_{2} \mathrm{O}$ and $\mathrm{CH}_{2} \mathrm{Cl}_{2}$ (entries 12,13), MeCN remained the best choice. Other solvents, such as toluene and dioxane, proved inferior (entries $14,15)$. Thus, the conditions in entry 11 were taken as optimal.

To investigate the reaction scope, the substrates were selected to represent diverse compound classes. The results are collected in Figure 1. On a standard $2 \mathrm{mmol}$ scale, benzonitrile 2a was isolated in a $98 \%$ yield. The reaction worked equally well on a $1 \mathrm{~g}(8.3 \mathrm{mmol})$ scale giving $\mathbf{2 a}$ in a $92 \%$ yield. Aromatic amides 1b-1f mirrored the reactivity of the model benzamide 1a furnishing the respective nitriles $\mathbf{2} \mathbf{b}-\mathbf{2 f}$ in high yields. A set of heterocyclic amides $\mathbf{1 g - 1 \mathbf { j }}$ were next assessed. 2-Cyanothiophene $\mathbf{2 g}$, 3-cyanopyridine $\mathbf{2} \mathbf{h}$ and 2-cyanoquinoline $\mathbf{2} \mathbf{i}$ were accessed in high yields. In this series, it is worth highlighting the efficient synthesis of the 3 -cyanotetrahydroisoquinoline derivative $\mathbf{2} \mathbf{j}$ from the corresponding amide $\mathbf{1 j}$. This compound serves as a precursor to the respective axially chiral tetrahydroisoquinoline$N, N$ '-dioxide, which belongs to a group of highly competent Lewis base catalysts for asymmetric crotylation of carbonyl compounds that are currently under investigation in our laboratories. ${ }^{17}$ Unsaturated cinnamamide $\mathbf{1 k}$, aliphatic linear (1), 1m) and branched (1n, 10) amides were converted into the respective nitriles in good yields, though their reactivity was somewhat lower compared to the aromatic analogues. The same applied to the functionalized derivatives 1p-r, which included phenoxyacetamide 1p and phthalimide protected amino acid amides 1q and 1r. It has to be noted that the corresponding $t$-Boc-protected amino acids did not give the desired nitrile. Instead, numerous side-products were formed, which most likely resulted from the reaction of the $N$-Boc group with oxalyl chloride, similar to the reaction shown in Scheme 2. 


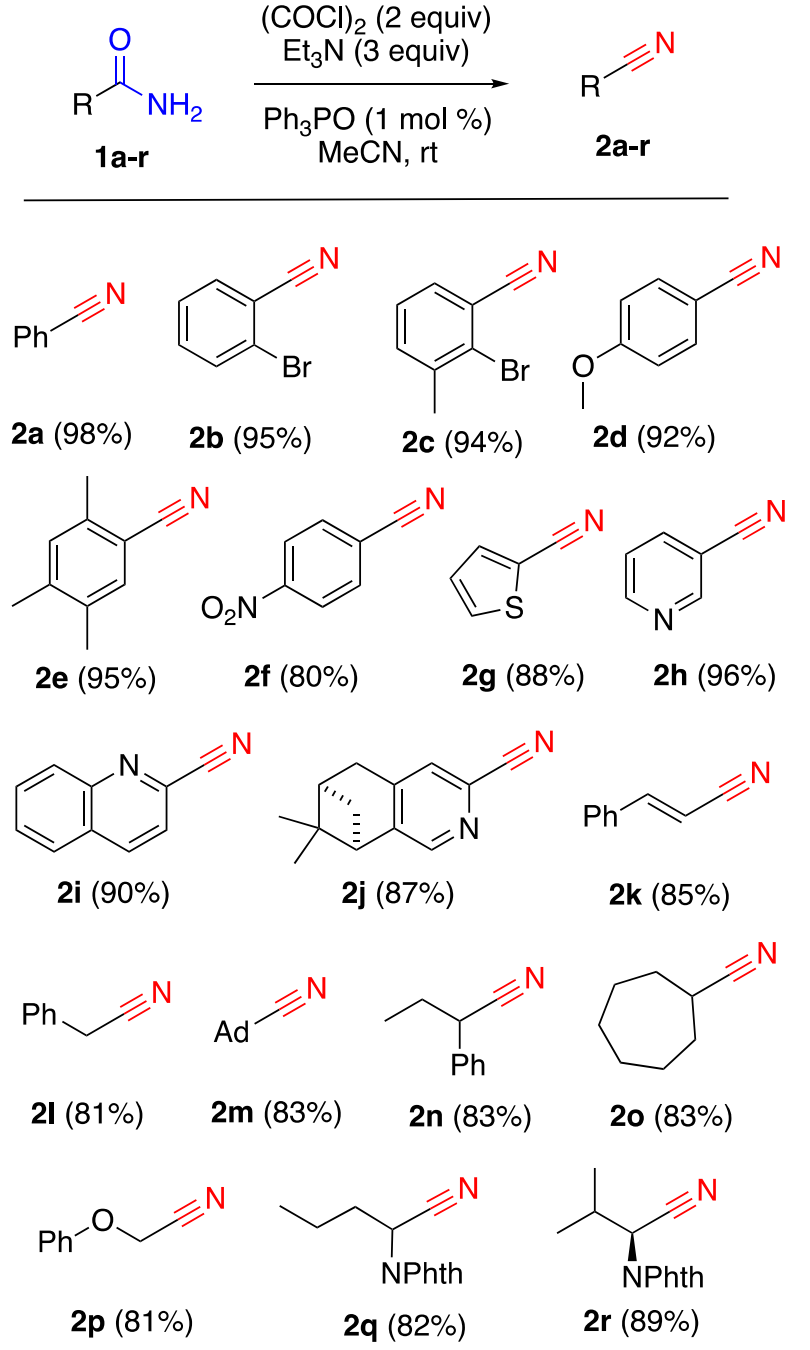

Figure 1. Catalytic dehydration scope. General conditions: amide 1 (2.0 mmol), $\mathrm{Ph}_{3} \mathrm{PO}$ (1 mol \%), $\mathrm{Et}_{3} \mathrm{~N}$ (3 equiv), dry MeCN $(8 \mathrm{~mL})$, dropwise addition of $(\mathrm{COCl})_{2}(2$ equiv). The reactions were carried out for $10 \mathrm{~min}$ at rt. Yields of the isolated compounds are given.

Based on the experimental observations and the published data on the catalytic Appel reaction, ${ }^{14-15}$ we suggest two possible mechanistic pathways for this dehydration reaction (Scheme 2). Both cycles start with a quick formation of the intermediate chlorophosphomium chloride $\mathbf{B}$ upon treatment of triphenylphosphine oxide $\mathbf{A}$ with $(\mathrm{COCl})_{2}$, as demonstrated by Denton with the aid of ${ }^{31} \mathrm{P}$ NMR spectroscopy. ${ }^{14 \mathrm{~d}} \mathrm{Next}$, in the catalytic cycle 1 , intermediate $\mathbf{B}$, in the presence of $\mathrm{Et}_{3} \mathrm{~N}$, reacts with amide $\mathbf{1}$ via oxygen to form first species $\mathbf{D}$ followed by species $\mathbf{E}$, which then undergoes elimination to furnish nitrile $\mathbf{2}$ and to regenerate triphenylphosphine $\mathbf{A}$; such a sequence was proposed by Appel. ${ }^{11}$ The pathway outlined in the catalytic cycle 2 that proceeds via formation of $N$-acyltriphenylphosphine imide $\mathbf{F}$ was originally rejected by Appel $^{11}$ because $\mathbf{F}$ was deemed too stable. Nonetheless, we decided to revisit this mechanistic option (see Supporting Information for details). $N$-Benzoyltriphenylphosphine imide synthesized by a literature method ${ }^{18}$ was first treated with 3 equiv of $\mathrm{Et}_{3} \mathrm{~N}$ in $\mathrm{MeCN}$. After $10 \mathrm{~min}$ at rt, conversion to nitrile $2 \mathrm{a}$ reached $30 \%$. However, when $\mathrm{Et}_{3} \mathrm{~N}$ was used in a combination with 1 equiv of $(\mathrm{COCl})_{2}$, a complete conversion to 2a was achieved almost instantaneously, thus making this route highly probable. Currently, by monitoring the reaction by NMR, we were unable to distinguish whether it proceeds through the intermediacy of $\mathbf{D}$ or $\mathbf{F}$ (or both) due to fast reaction times. Therefore, both catalytic cycles could be considered viable options. ${ }^{19}$

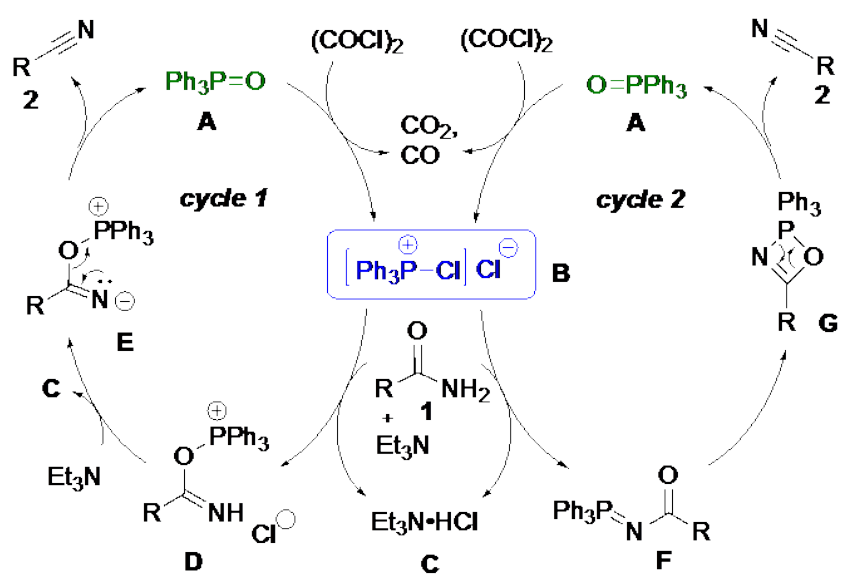

Scheme 3. Possible catalytic cycles for dehydration of amides to nitriles mediated by phosphine oxide.

In conclusion, we have developed a highly expedient protocol for a catalytic Appel-type dehydration of amides to nitriles catalyzed by triphenylphosphine oxide The salient features of the method are (i) operationally simplicity, (ii) low catalyst loading (1 mol \%), (iii) fast reaction times, (iv) mild conditions and (v) wide reaction scope that includes aromatic, heteroaromatic and aliphatic amides, including functionalized derivatives.

\section{ASSOCIATED CONTENT}

\section{Supporting Information}

Experimental procedures; ${ }^{1} \mathrm{H}$ and ${ }^{13} \mathrm{C}$ NMR spectra for new compounds.

The Supporting Information is available free of charge on the ACS Publications website.

\section{AUTHOR INFORMATION}

\section{Corresponding Author}

*E-mail: A.Malkov@lboro.ac.uk

*E-mail: Rubtsov@psu.ru

\section{Author Contributions}

The manuscript was written through contributions of all authors.

\section{ACKNOWLEDGMENT}

The authors thank Russian Science Foundation for grant 15-1300092. We also acknowledge RUDN University and the Ministry of Education and Science of the Russian Federation (the Agreement 02.A03.21.0008) for access to the analytical facilities (HRMS).

\section{REFERENCES}

(1) (a) Fatiadi, A. J., Preparation and synthetic applications of cyano compounds. In Triple-Bonded Functional Groups, Patai, S.; Rappoport, Z., Eds. John Wiley \& Sons, Ltd.: Chichester, UK., 1983; Vol. 2. (b) Miller, J. S.; Manson, J. L. Acc. Chem. Res. 2001, 34, 563570.

(2) (a) Gaspar, B.; Carreira, E. M., Angew. Chem. 2007, 119, 4603-4606. (b) Kukushkin, V. Y.; Pombeiro, A. J. L. Chem. Rev. 2002, 102, 1771-1802. 
(3) Fleming, F. F.; Yao, L.; Ravikumar, P. C.; Funk, L.; Shook, B. C. J. Med. Chem. 2010, 53, 7902-7917.

(4) Fleming, F. F. Nat. Prod. Rep. 1999, 16, 597-606.

(5) (a) Smith, M. B.; March, J., Eliminations. In March's Advanced Organic Chemistry: Reactions, Mechanisms, and Structure, Sixth ed.; John Wiley \& Sons, Inc.: Hoboken, NJ, USA, 2006; pp 15491550. (b) Bhattacharyya, N. K.; Sangeeta, J. S. J.; Bhutia, T. Y.; Adhikary, G. Int. J. Chem. App. 2012, 4, 295-304.

(6) Paquin, J.-F.; Keita, M.; Vandamme, M. Synthesis 2015, 47, 3758-3766.

(7) Itagaki, S.; Kamata, K.; Yamaguchi, K.; Mizuno, N. ChemCatChem 2013, 5, 1725-1728.

(8) (a) Elangovan, S.; Quintero-Duque, S.; Dorcet, V.; Roisnel, T.; Norel, L.; Darcel, C.; Sortais, J.-B. Organometallics 2015, 34, 45214528. (b) Zhou, S.; Addis, D.; Das, S.; Junge, K.; Beller, M. Chem. Commun. 2009, 45, 4883-4885. (c) Xue, B.; Sun, H.; Wang, Y.; Zheng, T.; Li, X.; Fuhr, O.; Fenske, D. Chem. Commun. 2016, 86, 148-150.

(9) (a) Enthaler, S.; Inoue, S.. Chem.-Asian J. 2012, 7, 169-175. (b) Enthaler, S.. Chem.—Eur. J. 2011, 17, 9316-9319.

(10) Zhang, W.; Haskins, C. W.; Yang, Y.; Dai, M. Org. Biomol. Chem. 2014, 12, 9109-9112.

(11) Appel, R.; Kleinstück, R.; Ziehn, K. D. Chem. Ber. 1971, 104, 1030-1034.

(12) (a) Appel, R. Angew. Chem., Int. Ed. 1975, 14, 801-811. (b) Lee, R. J.; Lindley, M. R.; Pritchard, G. J.; Kimber, M. C. Chem. Commun. 2017, 53, 6327-6330.

(13) Dow, K.; Downing, T. E., An Atmospheric Life Time of 85 Years has been Ascribed to $\mathrm{CCl}_{4}$. In The Atlas of Climate Change, University of California Press: Berkeley, 2006.

(14) (a) Denton, R. M.; An, J.; Adeniran, B. Chem. Commun. 2010, 46, 3025-3027. (b) Denton, R. M.; Tang, X.; Przeslak, A. Org. Lett. 2010, 12, 4678-4681. (c) An, J.; Denton, R. M.; Lambert, T. H.; Nacsa, E. D. Org. Biomol. Chem. 2014, 12, 2993-3003. (d) Denton, R.
M.; An, J.; Adeniran, B.; Blake, A. J.; Lewis, W.; Poulton, A. M. J. Org. Chem. 2011, 76, 6749-6767.

(15) (a) Rajendran, K. V.; Gilheany, D. G. Chem. Commun. 2012, 48, 817-819. (b) Nikitin, K.; Müller-Bunz, H.; Gilheany, D. Chem. Commun. 2013, 49, 1434-1436. (c) Yu, T. Y.; Wang, Y.; Xu, P. F. Chem.-Eur. J. 2014, 20, 98-101. (d) Kenny, N. P.; Rajendran, K. V.; Gilheany, D. G. Chem. Commun. 2015, 51, 16561-16564.

(16) (a) Couturier, M.; Caron, L.; Tumidajski, S.; Jones, K.; White, T. D. Org. Lett. 2006, 8, 1929-1932. (b) Speziale, A. J.; Smith, L. R. J. Org. Chem. 1963, 28, 1805-1811.

(17) (a) Incerti-Pradillos, C. A.; Kabeshov, M. A.; O'Hora, P. S.; Shipilovskikh, S. A.; Rubtsov, A. E.; Drobkova, V. A.; Balandina, S. Y.; Malkov, A. V. Chem.-Eur. J. 2016, 22, 14390-14396. (b) O'Hora, P. S.; Incerti-Pradillos, C. A.; Kabeshov, M. A.; Shipilovskikh, S. A.; Rubtsov, A. E.; Elsegood, M. R.; Malkov, A. V. Chem.-Eur. J. 2015, 21, 4551-4555.

(18) Froyen, P. Phosphorus, Sulfur Silicon Relat. Elem. 1993, 78, 161-171.

19. One of the reviewers suggested another possible mechanistic scenario for the dehydration of amides using the same set of reagents: imidate $\mathbf{4}$ formed by $\mathrm{O}$-acylation of $\mathbf{1}$ (Scheme 2) reacts with triphenylphosphine oxide to give the active intermediate $\mathbf{D}$ which is then deprotonated by triethylamine to yield $\mathbf{2}$ (Scheme 3). While we cannot rule out such a possibility, our optimization experiments (Table 1, entries 1 and 2) suggest that if the imidate $\mathbf{4}$ was formed in appreciable quantities, we should have observed formation of the respective acyl isocyanates, which were not detected under the optimized reaction conditions. Therefore, this route appears to be less likely than the two shown in Scheme 3. 